\title{
O discurso sobre o professor mediador: uma reflexão sobre produções discursivas de licenciandos na educação a distância
}

Rosângela Hammes Rodrigues* Nivea Rohling**

\section{Resumo}

Este artigo apresenta uma análise de produções discursivas de licenciandos em Letras de um curso de Licenciatura Letras-Português-EaD de uma universidade pública federal do sul do Brasil. Objetiva-se investigar a constituição identitária do professor de língua portuguesa. A fundamentação teórico-metodológica baseia-se nos estudos do Círculo de Bakhtin. Os dados analisados compõem-se de 106 fóruns de discussão; 59 enunciados de atividades avaliativas, postados no ambiente virtual de ensino e aprendizagem no período de 2007 a 2011; e dados gerados por meio de um questionário respondido por 61 licenciandos. A análise das produções discursivas dos licenciandos aponta para a reenunciação de vários discursos sobre o professor, dentre eles o do professor mediador. O professor mediador é significado pelos licenciados como mediador do conhecimento, como alguém que está entre o conhecimento e o aluno, o que nos remete ao sentido de transposição de conteúdos.

Palavras-chave: Produção discursiva na Educação a Distância. Formação inicial do professor. Professor mediador. Círculo de Bakhtin.

\section{Introdução}

Neste texto apresentamos uma análise de produções discursivas de um grupo de sujeitos em formação inicial de um curso de licenciatura em língua portuguesa no âmbito da educação a distância de uma universidade pública do sul do Brasil. Inserido em um contexto mais amplo de reflexão epistemológica acerca da constituição identitária do professor de Língua Portuguesa, este estudo analisa e problematiza as diferentes orientações axiológico-discursivas enunciadas pelos licenciados no tocante

\footnotetext{
Doutora em Linguística Aplicada pela PUC/SP. Docente do Departamento de Língua e Literatura Vernáculas, professora do Programa Mestrado Profissional em Letras e do Programa de Pós-Graduação em Linguística da UFSC.

** Doutora em Linguística pela UFSC. Docente do Departamento Acadêmico de Comunicação e Expressão da UTFPR/Campus Curitiba.
}

\footnotetext{
Data de submissão: jul. 2014 - Data de aceite: ago. 2014 http://dx.doi.org/10.5335/rdes.v10i2.4110
} 
à atuação docente, dentre as quais se destaca o discurso sobre o professor mediador, objeto de estudo deste artigo. Essa análise nos permite refletir sobre os modos como o fazer docente do professor de língua portuguesa é discursivizado na formação inicial hoje.

Para tanto, inicialmente apresentamos conceitos teóricos centrais da análise empreendida, tendo como escopo teórico e metodológico os estudos do Círculo de Bakhtin. A seguir, apresentamos o percurso metodológico do estudo a fim de descrever a constituição dos dados bem como os parâmetros analíticos empreendidos. Na sequência, já como resultado da análise, problematizamos a constituição histórica da identidade do professor. Por fim, discutimos as regularidades observadas na análise dos dados no que se refere ao discurso do professor mediador (re)enunciado pelos licenciados.

\section{Concepção de sujeito e de linguagem}

Em um estudo ancorado teórico e metodologicamente nos estudos do Círculo de Bakhtin são conceitos centrais a noção de linguagem, discurso, enunciado, sujeito e dialogismo, que foram balizas para a análise aqui apresentada.

Neste quadro epistemológico, a linguagem é vista como discurso, tendo em vista que se trata da própria língua em sua integridade concreta e viva. Ao empreender uma análise do discurso nessa perspectiva teórica, é preponderante tomar a língua no seu aspecto histórico e concreto, uma vez que o discurso não se constrói sobre uma determinada realidade sem a relação constitutiva com o outro, ou seja, numa relação de respondibilidade a outro discurso. De acordo com Bakhtin [Volochínov] 2004[1929], a comunicação verbal não poderá jamais ser compreendida e explicada fora do vínculo com a situação concreta. Para se conceber a linguagem sem perder de vista o caráter dinâmico de uma abordagem de cunho sócio-histórica, é necessário considerar que o ponto de partida para a análise do discurso (materializado nos enunciados) são, inicialmente, os estratos sociais mais amplos, para então compreender a materialidade linguística.

Além disso, para Bakhtin,

O estudo do discurso verbal implica um olhar para as relações dialógicas, pois a linguagem só vive na comunicação dialógica daqueles que a usam (BAKHTIN, 2008[1963], p. 209, grifo do autor).

Assim, o autor ressalta o estatuto da palavra do outro (o discurso do outro) - a qual requer sempre uma compreensão ativa e uma atitude responsiva-ativa - na constituição da nossa palavra. A discussão sobre o papel da compreensão ativa e a presença do outro como constituintes do discurso constitui a base de sua teoria dialógica da linguagem ao relacionar o discurso ao diálogo, no sentido amplo do termo, sustentando a noção de que o discurso tem eminentemente uma natureza dialógica. Nas palavras do autor, 
[...] a orientação dialógica é naturalmente um fenômeno próprio a todo discurso [...] todo discurso nasce no diálogo como sua réplica viva, forma-se na mútua-orientação dialógica do discurso de outrem no interior do objeto. A concepção que o discurso tem do objeto é dialógica (BAKHTIN, 1998[1975], p. 88-89).

Essa orientação dialógica do discurso - dialogicidade interna do discurso que penetra os estratos semânticos e expressivos da língua - manifesta-se de duas formas: pela orientação para o já-dito e pela orientação para a resposta antecipada do outro.A orientação dialógica se constrói na atmosfera do já-dito, ou seja, para o já conhecido, pois todo objeto já é contornado de opiniões sociais sobre ele. Sobre a orientação para o já-dito, Bakhtin escreve: "o objeto é para o prosador a concentração de vozes multidiscursivas, dentre as quais deve ressoar a sua voz; essas vozes criam o fundo necessário para a sua voz [...]"; e, ainda: "[...] em todas as direções, o discurso se encontra com o discurso de outrem e não pode deixar de participar com ele, de uma interação viva e tensa." (BAKHTIN, 1998[1975], p. 88). Além de se constituir na atmosfera do já-dito, o discurso nasce e vive na relação constitutiva com a reação-responsiva, uma vez que o discurso se constitui também a partir do discurso que ainda não foi proferido, mas foi solicitado, é esperado na relação discursiva. Segundo Bakhtin (1998[1975], p. 89), “o discurso vivo e coerente está imediata e diretamente determinado pelo discurso-resposta futuro: ele é que provoca esta resposta, pressente-a e baseia-se nela". Ou seja, nas interações discursivas, o outro se insere no meu discurso, não é mero ouvinte passivo, uma vez que moldamos o nosso enunciado em virtude desse interlocutor e da sua reação-resposta ativa. Tanto a compreensão ativa quanto a resposta ativa são partes inerentes a todo discurso, que, por sua vez, só é possível na/ pela relação dos falantes em situações de interação discursivas situadas.

É essa perspectiva de linguagem que orienta a análise bakhtiniana de produções discursivas de diferentes esferas sociodiscursivas. Segundo Brait (2007), é possível dizer que a arquitetônica bakhtiniana fornece elementos que contribuem para um caminho, em outras palavras, horizontes possíveis para se estudar a linguagem e os discursos numa perspectiva dialógica.

Ao tentar definir esse horizonte teórico-metodológico, Brait escreve:

Sem querer (e sem poder) estabelecer uma definição fechada do que seria essa análise/ teoria dialógica do discurso, uma vez que o fechamento significaria uma contradição em relação aos termos que a postulam, é possível explicar seu embasamento constitutivo, ou seja, a indissolúvel relação existente entre língua, linguagens, história e sujeitos que instaura os estudos da linguagem como lugares de produção de conhecimento de forma comprometida, responsável, e não apenas como procedimento submetido a teorias e metodologias dominantes em determinadas épocas (BRAIT, 2006, p. 10).

Conforme se pode inferir da citação da autora, a impossibilidade de fechamento, ou seja, de estabelecimento de uma metodologia de análise rígida, está no 
centro da arquitetônica bakhtiniana. De acordo com a pesquisadora, essa opção epistêmica não se reduz à aplicação de uma metodologia e validação de teorias, mas ao construto de conhecimentos relevantes e responsáveis no âmbito dos estudos da linguagem.

A fim de construir parâmetros teórico-analíticos para a análise de discurso em uma perspectiva dialógica, Brait (2006) expõe algumas peculiaridades de tais pesquisas. Primeiramente, a análise inclui um olhar particular para as práticas discursivas, ou seja, para as enunciações concretas e, por isso, ao mesmo tempo, leva em conta os contextos mais amplos de produção e circulação dos discursos. Em outras palavras, o enfrentamento bakhtiniano da linguagem leva em conta as particularidades discursivas, que apontam para contextos mais amplos ao considerar os aspectos extralinguísticos imbricados.

Outro ponto a ser observado, segundo Brait (2006), é que em uma análise bakhtiniana não há categorias a priori aplicáveis de forma mecânica a textos e discursos. Nessa perspectiva epistemológica, as categorias emergem das relativas regularidades dos dados, que são observadas/apreendidas no percurso da pesquisa. Não se podem aplicar as mesmas categorias de uma pesquisa já feita a outra, pois o dado é sempre o discurso concreto e único proferido em um determinado espaço e tempo e por determinados interlocutores. No âmbito da produção de conhecimento, certamente é necessário olhar o único, o singular, o evento, que conduz a uma certa regularidade.

De forma mais pontual, Sobral (2007b, p. 114) propõe alguns aspectos a serem observados em uma pesquisa cuja base teórico-metodológica é o pensamento bakhtiniano. São eles:

- a relação entre os aspectos generalizáveis e os aspectos particulares do fenômeno, que constitui o plano teórico;

- a relação entre as expectativas do pesquisador e a realidade do fenômeno, base da construção do objeto de que o pesquisador se ocupa, que constitui o plano ético;

- o caráter de construção arquitetônica de toda pesquisa, que constitui o plano estético.

Por fim, vale destacar que na pesquisa de análise de discurso nessa perspectiva teórica há também análise das marcas linguísticas. Contudo, trata-se de um olhar para a língua vista na condição de discurso, em outras palavras, a língua na sua condição de mediadora das interações; trata-se de uma análise da linguagem em uso, do funcionamento discursivo em dada situação de interação discursiva. Tal estudo caracteriza-se por uma análise semântica que leva em conta as relações extralinguísticas, históricas e concretas, que se materializam nos enunciados, com vistas a construir compreensões sobre os sentidos promovidos no bojo das relações dialógicas.

Por isso, é preciso considerar que a análise de discurso numa perspectiva 
bakhtiniana é uma proposta de análise, uma via de investigação, uma maneira de interrogar e não um método de pesquisa ou modelo rígido de escrita (AMORIM, 2004, p. 16).

Tendo, pois, apresentado em linhas gerais alguns parâmetros para desenvolvimento de análise de discurso na perspectiva dos estudos do Círculo de Bakhtin, na seção a seguir explicitamos os aspectos metodológicos mais específicos do estudo em tela.

\section{Percurso metodológico}

Este estudo parte da noção de que os dados são gerados/constituídos ${ }^{1}$ no ato-evento de se fazer pesquisa, o que significa dizer que eles não estão prontos e acabados a priori. A constituição dos dados em uma pesquisa cuja base epistêmica é a arquitetônica bakhtiniana se dá a partir de uma tomada de posição exotópica (de extralocalização) do pesquisador frente ao campo de estudo. $\mathrm{O}$ pesquisador se aproxima do campo para conhecê-lo, porém distancia-se dele para auscultar, pensar e refletir sobre um conjunto de enunciados que materializam determinado discurso - no nosso caso, o discurso dos graduandos em Licenciatura Letras-Português na EaD sobre a atuação do professor de Língua Portuguesa.

Nesta análise, de modo mais específico, as regularidades discursivas foram observadas em dados constituídos em contexto de educação formal, mais precisamente em um curso de formação inicial de professores de Língua Portuguesa na EaD em uma universidade pública no sul do Brasil.

Os sessenta e um (61) licenciandos cuja produção discursiva compõe os dados desta pesquisa cursavam a sexta fase da primeira turma de Licenciatura Letras-Português na modalidade EaD da referida universidade, distribuída em 5 polos presenciais. Os dados compõem-se de 106 fóruns de discussão; 59 enunciados de atividades avaliativas, postados no ambiente virtual de ensino e aprendizagem no período de 2007 a 2011; e dados gerados por meio de um questionário, respondido pelos licenciados nos seus respectivos polos de apoio de ensino presencial.

Segundo o projeto pedagógico do curso, o processo seletivo para a primeira edição do curso (2008) foi aberto ao público em geral, no entanto, o preenchimento de vagas deu prioridade de acesso aos professores em exercício nas redes públicas de ensino que estavam atuando nos anos/séries finais do Ensino Fundamental e/ou no Ensino Médio, mas sem licenciatura na disciplina.

A maioria dos licenciandos participantes da pesquisa são adultos e trabalhadores, o que significa dizer que são sujeitos inseridos em várias instâncias discursivas - cotidiana, familiar, profissional -, e, em cada uma delas, ocupam uma posição sociodiscursiva.

Assim sendo, para a análise da produção discursiva dos licenciandos do curso de Licenciatura Letras-Português-EaD, 
apoiamo-nos em alguns parâmetros analíticos apresentados nas análises empreendidas pelo Círculo de Bakhtin. Esses parâmetros foram basilares para a compreensão dos sentidos dos discursos dos licenciandos no que se refere à atuação docente. São eles:

- o estudo da esfera de atividade humana em que se dão as interações discursivas em foco;

- a descrição dos papéis assumidos pelos participantes da interação discursiva, analisando as relações simétricas/assimétricas entre os interlocutores na produção de discurso;

- o estudo do cronotopo (o espaço-tempo discursivo) dos enunciados;

- o estudo do horizonte temático-valorativo dos enunciados;

- a análise das relações dialógicas que apontam para a presença de assimilação de discursos já-ditos e discursos prefigurados (reação resposta antecipada), discursos bivocais, apagamentos de sentidos, contraposições, enquadramentos, reenunciação de discursos e reacentuações de discursos.

Em suma, o foco da análise foram as regularidades discursivas materializadas na produção discursiva dos licenciando a fim de observar a discursividade sobre a identidade do professor de Língua Portuguesa.

A seguir, já como resultado da pesquisa, problematizamos as diferentes orientações valorativas no que se refere à identidade do professor, constituídas nos processos históricos da esfera escolar.

\section{A constituição histórica da identidade do professor}

No texto A aula como acontecimento, Geraldi (2010a) ${ }^{2}$ reflete sobre os modos como a profissão de professor foi sendo delineada no curso das interações concretizadas na esfera escolar ao longo do tempo. De acordo com o pesquisador, a identidade do professor tem sido desenhada através de forças/contingências advindas da divisão social do trabalho, que produziram três modos de construir e significar a identidade do professor: 1 . o professor é um sábio; 2. o professor é alguém que transmite um saber produzido por outro; 3. o professor é alguém que aplica um conjunto de técnicas de controle em sala de aula.

Conforme Geraldi, antes da estabilização da visão contemporânea de escola, o que se tinha era a chamada escola de sábios, que reunia sujeitos, não na condição de alunos, mas de discípulos, como, por exemplo, as escolas de sofistas, as escola de Sócrates, a escola de Platão ou, ainda, os conventos da Idade Média. Nessa época, não havia distinção entre o filósofo e o professor de filosofia, pois "havia um produtor de conhecimentos, e esse produtor de conhecimentos, porque produtor, era buscado por seguidores" (GERALDI 2010a, p. 83). O autor observa que essa forma de ensino (entre o sábio e o conhecimento e entre o sábio e os discípulos) desaparece na história dos sistemas escolares. Ainda segundo o autor, talvez as relações entre orientadores e orien- 
tandos, nos programas de pós-graduação, configurem-se como os últimos resquícios desse modo de ensino e aprendizagem.

Já no período do Mercantilismo ocorre a primeira grande divisão social do trabalho educativo, o que leva à constituição da segunda identidade do professor. Nesse período, havia muitas pessoas que precisavam aprender, mas não havia pessoas doutas suficientes para ensinar e algo deveria ser feito para suprir essa demanda. Então, para resolver o problema, o professor não mais precisaria ser um sábio, alguém que construísse o conhecimento, "e sim saber tudo que deve fazer, e este 'tudo' lhe é dado nas mãos pelos doutores, que preparariam o que ensinar e como ensinar" (GERALDI, 2010a, p. 85). O professor passa de produtor de conhecimento para um sujeito que sabe o saber produzido por outros e, porque sabe, transmite-o a seus alunos. Essa é a segunda identidade, a do "professor como aquele que tem um saber e porque sabe, repassa a outros" (GERALDI, 2010a). Geraldi sumariza as características identitárias da profissão professor construídas nesse período da seguinte forma:

1. ser hábil para ensinar, mesmo não sendo muito dotado;

2. sua função é comunicar (e infundir) na juventude uma erudição já preparada, e não retirada da própria mente (isto é, não precisa ser produzida por ele próprio);

3. para exercer sua função, tudo se lhe dá nas mãos: o quê e o como ensinar (uma partitura já composta) (GERALDI, 2010a, p. 85).
A partir dessa incursão histórica é possível dizer que a profissão de professor emerge sob o signo da divisão entre produção de conhecimentos e transmissão de conhecimentos. Historicamente se consolidou a visão do professor como o detentor ${ }^{3}$ do saber/conhecimento e a quem é dada a tarefa de transmitir aos educandos os conhecimentos produzidos na cultura. Essa forma de conceber o professor está ancorada na tradição escolar e incide na própria constituição do sujeito professor. Em outras palavras, a identidade do professor se confunde com a tradição escolar. Parece haver um consenso de que ser professor significa necessariamente ser um sujeito que detém um conjunto de conhecimentos em determinada área e que também tem habilidades para repassá-los aos alunos. Isso porque os processos educacionais se caracterizam pelo objetivo de "transmitir às novas gerações o conjunto das experiências do passado, sistematizado na forma de valores, saberes e conhecimentos" (GERALDI, 2010b. p. 128). Assim é que, por um longo tempo, as práticas escolares foram assentadas na perspectiva de transmissão de conteúdos científicos e/ou culturais, ${ }^{4}$ instanciada por uma relação de transposição desse conhecimento teórico para um conhecimento pedagógico.

A terceira identidade do professor discutida por Geraldi (2010a) refere-se a que ocorreu na segunda revolução industrial e no início do Século XX. De novo, essa nova divisão do trabalho altera a identidade do professor, que 
[...] já não mais se define por saber o saber produzido pelos outros, que organiza e transmite didaticamente a seus alunos, mas se define como aquele que aplica um conjunto de técnicas de controle na sala de aula (GERALDI, 2010a, p. 86).

É nesse período que a relação entre aluno e conhecimento passa a acontecer por meio do material didático. Conforme Geraldi, ao professor "compete distribuir o tempo, distribuir as pessoas, e verificar se houve 'fixação' do conteúdo" (GERALDI, 2010a, p. 87). Delineou-se então a noção de professor como um transmissor de conteúdos com base em um ensino de reprodução de conhecimentos didáticos/ escolares não mais elaborados pelo professor, mas pelo autor do livro didático.

Sobre essa questão, Rojo (2001, p. 332) pondera que:

[...] o professor abriu mão de uma de suas atribuições básicas - a de ser "dono da voz", isto é, a de planejar seu ensino de acordo com as necessidades e possibilidades de seus alunos -, em favor do que é feito pelos autores dos livros didáticos, assumindo, de bom grado, uma posição de animador de sala de aula, cujo planejador e executor é o discurso do livro didático.

Acreditamos que essas três identidades do professor discutidas por Geraldi (2010a) ainda coexistem hoje na esfera escolar, embora com saliências e intensidades diferentes. Por exemplo, na universidade, temos ainda professores que produzem saberes científicos (os sábios); na educação básica, temos o professores que produzem saberes no âmbito da prática pedagógica (os sábios); na universidade e na educação básica também temos professores que elaboram suas aulas a partir dos saberes produzidos por outros e os professores que reproduzem conteúdos escolares não mais elaborados por eles e sim pelo autor do livro didático, por isso sua atuação central está no controle do tempo, dos sujeitos etc.

Essas identidades, que se imbricam na esfera escolar, constituíram-se na/ pela relação do professor com o conhecimento, destacando-se, na tradição escolar, a visão do professor como transmissor de conhecimentos (tanto científicos como escolares). A partir dessa relação constitutiva entre o professor e o conhecimento, emerge mais recentemente, na esfera escolar, a concepção de professor mediador, que aponta para uma nova identidade docente.

Assim, na seção a seguir, mostramos que o discurso do professor mediador se constitui como um contradiscurso ao discurso do professor transmissor de conhecimentos. Discutimos também de forma mais detalhada os modos como o discurso do professor mediador foi construído na esfera escolar, o que nos leva à observação de que seu sentido ancora-se, inicialmente, no conceito vigotskiano de mediação simbólica. No entanto, esse sentido vigotskiano, na esfera escolar, já não corresponde ao conceito elaborado por Vigotski.

\section{O discurso sobre o professor mediador}

O discurso sobre a relação entre o professor e o conhecimento mostrou-se nas produções discursivas dos licenciandos principalmente atrelada à noção de pro- 
fessor como mediador do conhecimento. Para compreender tais enunciados, é preciso atentar para a forma como tal concepção foi construída historicamente na esfera escolar.

No percurso histórico da esfera escolar, de um modo geral, a perspectiva do professor como transmissor de conhecimentos foi relacionada ao ensino considerado como tradicional. No final da década de 1970 e início da década de 1980, observamos, no campo do ensino e aprendizagem de modo geral, a emergência de um discurso-resposta que questiona as práticas pedagógicas balizadas pela noção de transmissão de conhecimentos, que passam a ser consideradas tradicionais pelos estudos científicos. Esse período é bastante singular no que se refere aos novos modos de pensar o ensino e a aprendizagem e, consequentemente, à atuação do professor. É nessa época que emerge o discurso da pedagogia crítica de Paulo Freire, com a publicação do livro A pedagogia do oprimido, em 1970. Freire (2005[1970]) intitula educação bancária a prática pedagógica em que o professor é tido como o detentor do saber e o aluno como alguém que nada sabe e a quem os conteúdos devem ser repassados/transmitidos/depositados. Para Freire (2006[1996], p. 22, grifos do autor), "ensinar não é transferir conhecimento, mas criar as possibilidades para a sua produção ou a sua construção".

$\mathrm{Na}$ área de ensino de língua materna, no início da década de 1980, vemos eclodir a crítica, motivada pelos estudos linguísticos, ao ensino prescritivo da língua, conforme historiam Britto (1997) e Soares (2002). Segundo R. H. Rodrigues (2008, p. 170), as críticas ao ensino tradicional de língua portuguesa na escola focalizaram

[...] a leitura de fragmentos de textos, as práticas descontextualizadas e sem sentido de produção de textos e o conteúdo gramatical (ausência de finalidade, excesso de teoria gramatical e adequação do conhecimento advindo da gramática tradicional).

Podemos dizer que as críticas da academia ao ensino de Língua Portuguesa focalizaram, sobretudo, as finalidades e os conteúdos da disciplina e não somente aspectos ligados à metodologia.

Além disso, nessa mesma época, os estudos do psicólogo Lev Semionovich Vigotski começam a ecoar nas pesquisas brasileiras em educação, mais precisamente em psicologia da educação. Vigotski elaborou um produtivo quadro epistêmico, que inclui temas intrinsecamente ligados, como a relação entre pensamento e linguagem, as funções psicológicas superiores, os conhecimentos cotidianos e científicos, os processos de internalização dos conceitos etc. Nessa elaboração teórica, destacamos o conceito de mediação, que, para Vigotski (1991[1984]), tem caráter essencialmente semiótico, constitui-se nas relações entre o intersubjetivo e o intrassubjetivo e é a base para o desenvolvimento dos processos psicológicos superiores. $\mathrm{Na}$ obra de Vigotski, o termo mediação ou elo de mediação refere-se a um processo complexo, em que o sujeito, na interação com o outro e com o meio, torna intrassubjetivos os conhecimentos cons- 
truídos e compartilhados no âmbito do intersubjetivo, no interior das atividades humanas. Nesse processo, o mediador é a linguagem, via signo, uma vez que a mediação é uma atividade simbólica que se dá por meio da interação entre sujeitos situados social, histórica e culturalmente. Assim, a mediação é um processo que nasce na relação de alteridade entre sujeitos sócio e historicamente situados, o que significa dizer que esse conceito vigotskiano tem uma dimensão eminentemente política e ideológica.

A noção de mediação simbólica de Vigotski também pode ser relacionada à noção de interação de Bakhtin, uma vez que, na perspectiva bakhtiniana, o sujeito se constitui nas relações estabelecidas na confluência entre externo e o interno, ou seja, entre a dimensão individual e a dimensão social dos processos interacionais. Nessas relações, a linguagem é o elemento fundador da articulação entre o social e o individual (FARACO, 2009[2003]).

Vigotski e Bakhtin compreendem a linguagem como um construto social, histórico e semiótico, e, por isso, a mediação (na visão de Vigotski) e a interação (na visão de Bakhtin) não se encontram na individualidade dos sujeitos, mas na relação de alteridade, constituída pela linguagem. Além disso, para ambos os autores, não se pode separar tais processos (de mediação e de interação) das questões ideológicas implicadas.

Assim, o discurso do professor mediador constituiu-se no contradiscurso ao discurso do professor como transmissor de conhecimentos (considerado tradicional) e numa reinterpretação da noção de mediação simbólica de orientação vigotskiana, que foi assimilada pelos documentos oficiais de ensino.

A expressão professor mediador foi incorporada pelos Parâmetros Curriculares Nacionais (1998), que apontam as três variáveis no ensino e aprendizagem de língua portuguesa: o aluno; os conhecimentos com os quais se operam nas práticas de linguagem e a mediação do professor (BRASIL, 1998, p. 22, grifo nosso).

$\mathrm{O}$ uso do termo professor mediador aparece textualmente nos excertos a seguir:

[...] valorizar os trabalhos dos docentes como produtores, articuladores, planejadores das práticas educativas e como mediadores do conhecimento socialmente produzido [...]. (BRASIL, 1998, p. 11, grifo nosso).

A conquista dos objetivos propostos para o ensino fundamental depende de uma prática educativa que tenha como eixo a formação de um cidadão autônomo e participativo. Essa prática pressupõe que os alunos sejam sujeitos de seu processo de aprendizagem e que construam significados para o que aprendem, por meio de múltiplas e complexas interações com os objetos de conhecimento, tendo, para tanto, o professor como mediador (BRASIL, 1998, p. 81, grifo nosso).

Como podemos observar, o conceito de mediador proposto pelos PCNs parece apontar para o sentido de estar entre. De acordo com o documento, os estudantes devem construir "complexas interações com os objetos de conhecimento, tendo, para tanto, o professor como mediador" (BRASIL, 1998, p. 81). Nessa perspectiva, o professor está colocado no meio, ou 
seja, está entre os alunos e os objetos de conhecimento. Essa noção de mediação distancia-se da noção de mediação oriunda dos estudos vigotskianos, pois, como dito antes, para Vigotski, a noção de mediação é mais ampla, tendo um caráter ontológico e ideológico, o que tem implicações nas relações intersubjetivas que envolvem a linguagem e a interação entre sujeitos socio e historicamente constituídos.

A perspectiva vigotskiana de mediação extrapola a concepção restrita de interposição entre aluno e objeto de conhecimento, tal qual o conceito de mediação dos PCNs parece apontar. É possível dizer também que a posição dos PCNs reduz a noção de mediação a um conceito metodológico e procedimental. Mais que isso, apaga as marcas ideológicas implicadas, tendo em vista que, no conceito de mediação de Vigotski, há antes de tudo interação entre os sujeitos historicamente situados: o professor, alguém mais experiente e constituído pelo seu horizonte valorativo, e os alunos, também constituídos por horizontes valorativos próprios. Há, antes de tudo, um encontro/confronto de axiologias, construídas nas relações de alteridade.

Como mostramos, inicialmente o conceito de mediação foi gestado em um contexto epistêmico (estudos vigotskianos), sendo assimilado na esfera escolar, que, por sua vez, normalmente, enuncia o discurso do professor mediador a fim de marcar distanciamento do discurso do professor como um transmissor de conteúdos, que remete, nesse discurso, a uma concepção de escola e de professor tradicional. A partir disso, podemos dizer também que, na área de ensino de línguas, a noção de professor mediador se distancia da concepção/identidade de professor como um transmissor de conteúdos gramaticais destituídos das relações interacionais, como apontava a crítica reformadora do ensino de língua materna (BRITTO, 1997).

No entanto, apesar de o discurso escolar sobre o professor mediador se constituir como refutação/contraposição ao ensino tradicional e ao professor transmissor de conteúdos, a esfera escolar faz a interpretação do conceito vigotskiano de mediação a partir de seu horizonte apreciativo, o que faz com que ele não mais remeta ao que foi constituído nos estudos vigotskianos, uma vez que a mediação passa a ser entendida a partir de uma concepção instrumental e metodológica.

Tal reflexão encontra embasamento em Kleiman (2006, p. 80), quando a autora pondera que o uso do termo professor mediador tem origem na noção de mediação semiótica de Vigotski. Trata-se, então, como discurso já dito, de conceitos produzidos pela ciência que, ao entrar em contato com outras comunidades de uso (esfera escolar), assumem novos sentidos. Segundo Kleiman (2006, p. $80-81),{ }^{5}$ na perspectiva das comunidades de uso, muitas vezes, a noção de professor como mediador remete à metáfora espacial - aquele que está no meio, ou seja, aquele que assume um papel de intermediador. Tal posicionamento não implica uma construção conjunta do conhecimento; nesse contexto, a noção 
de mediador leva-nos a pensar naquele que exerce um papel intermediário entre dois sujeitos interessados numa negociação. O conceito de mediador (como um intermediador) oblitera o trabalho do professor, uma vez que apaga/neutraliza a dimensão política que caracteriza a docência (KLEIMAN, 2006).

Em resumo, a noção de mediação construída na pesquisa científica desliza/ migra para a esfera escolar, por meio dos documentos oficiais de ensino, dos livros didáticos e dos processos de formação inicial ou continuada dos professores. Porém, ao ser assimilada na esfera escolar, a compreensão ativa sobre a noção de mediação foi ressignificada e reacentuada, o que implicou uma leitura outra desse conceito do ponto de vista teórico-metodológico. Segundo N. C. Rodrigues (2011, p. 185),

[...] o surgimento de novas teorias sobre o ensino não apaga a historicidade da constituição do sujeito professor, cuja formação se constituiu em outro contexto, no qual a prática pedagógica era orientada por outros discursos, os quais continuam valorados na esfera da escola.

Essa incursão histórica e teórica sobre o conceito de mediação nos auxiliou na compreensão dos discursos dos licenciandos, que, reiteradas vezes, discursivizaram a identidade do professor como mediador. Nesses discursos sobre o professor mediador do conhecimento, há certo apagamento ou, ainda, um deslizamento do sentido de mediador tal qual concebido nos estudos vigotskianos para uma assimilação do conceito conforme entendido em muitos contextos escolares.
O discurso dos licenciandos aponta para a concepção da identidade do professor mediador, compreendido como alguém que se interpõe entre 0 aluno e o objeto de conhecimento (metáfora da ponte). E mais, apesar de enunciarem a concepção do professor mediador, esta ainda é vista na perspectiva do professor como transmissor de conhecimentos. Nesses discursos, identificamos enunciados que reenunciam o discurso do professor mediador, de modo mais amplo (e vago), sem relacioná-lo a conteúdos específicos do professor de Língua Portuguesa. Ou seja, tematizam o objeto de mediação como conhecimento ou conteúdo, remetendo a conteúdos escolares de forma geral. Por outro lado, identificamos enunciados que reenunciam o discurso do professor como mediador de conteúdos específicos de Língua Portuguesa, evocando, portanto, discursos já-ditos sobre os conteúdos de ensino e aprendizagem constituídos na tradição do ensino da disciplina de Língua Portuguesa.

A seguir apresentamos enunciados em que o discurso sobre o professor mediador remete à concepção de transmissão de conhecimentos.

De maneira geral, como você vê o professor de Língua Portuguesa hoje? O que é ser professor de Língua Portuguesa hoje?

Q6: ${ }^{6}$ Como um mediador de conhecimentos. $E$ estar preparado para esse novo mundo que está em nossa frente e a conexão entre eles. 
Q7: É o mediador para que seus alunos entendam uma matéria considerada dificil, mas muito importante no currículo escolar.

\section{F1}

\section{Fórum 1}

por Fernanda - quarta, 22 setembro 2010, 15:05

O professor é a figura mediadora que fará a interação com os sujeitos ativos, ou seja, o sujeito e objeto do conhecimento é organizada pelo professor.

O leitor não é somente aquele que lê os clássicos ou mesmo outros livros, a leitura está em todos os lugares: placas, lista telefônica, lojas, msn, e-mail etc... $\mathrm{Na}$ escola a leitura pode ser praticada de várias formas, usando a nossa linguagem de mundo e interando com a linguagem de mundo dos alunos.

Nesses enunciados, há discursos com pontos de convergência, uma vez que eles apontam apenas para uma mudança terminológica e não uma mudança conceitual em relação à posição do professor como transmissor de conteúdos. No lugar de repassar/transmitir, os licenciandos usam o termo mediar. Altera-se o modo de enunciar, isso é, usa-se mediar conteúdos no sentido de repassar conteúdos, mas não se altera a concepção/identidade do professor como transmissor de conteúdos escolares.

Isso nos revela que, no horizonte valorativo dos licenciandos, ainda se mostra bastante arraigada a noção de professor como aquele que domina um saber e, por isso, o repassa/transmite aos alunos.
Do mesmo modo, no enunciado de fórum (F1), observamos a recorrência do discurso sobre o professor mediador no sentido de transmissão de conhecimento, quando a licencianda concebe o professor como a figura mediadora que fará a interação com os sujeitos ativos, ou seja, o sujeito e objeto do conhecimento.

Em outra situação de interação, mais especificamente em uma atividade avaliativa, o discurso sobre o professor mediador no sentido de transmissor de conteúdos também se mostrou saliente, como vemos a seguir:

Afinal, qual é a função do professor de Lingua Portuguesa e Literatura?

AA1-Rute: A função do professor de língua portuguesa e literatura é ser um mediador, entre as diversas formas de conhecimento. Ao ensinar ler e escrever, e mostrar como funciona o mecanismo da língua portuguesa o professor tem a ferramenta necessária para introduzir a literatura, a fim de fazer a fixação do assunto tratado bem como familiarizar os alunos no mundo imaginário, a fim de que desfrute de novas experiências distintas da língua propriamente dita, ou seja no campo literário.

AA2-Iara: A função do professor de Língua Portuguesa e Literatura é intermediar o caminho para que o aluno chegue até o conhecimento necessário, que ele precisar ter para viver socialmente. Assim, o professor é o mediador, que ajuda os alunos a adquirirem conhecimentos $e$ também muitas vezes, mostrar a esses alunos os percursos certos que precisa percorrer para obter sucesso em sua vida. 
Vale destacar que os conteúdos temáticos da disciplina de Metodologia do Ensino de Língua Portuguesa e Literatura, que propôs a atividade em análise, e o livro da disciplina, contemplavam a discussão sobre mediação assentada na perspectiva socio-histórica de inspiração vigotskiana. Então, em resposta a essa atividade, é frequente a menção dos licenciandos ao professor mediador. Contudo, embora a teorização da disciplina tenha apresentado aos licenciandos a abordagem epistemológica vigotskiana, o discurso por eles enunciado remete ao sentido de professor como alguém que transmite/repassa um saber, como se verifica em: [...] é ser um mediador, entre as diversas formas de conhecimento.

Rute (AA1) parece, em certo momento, mostrar um olhar um pouco mais centrado na atuação do professor de Língua Portuguesa, ao mencionar que cabe ao professor ensinar ler e escrever, e mostrar como funciona o mecanismo da língua portuguesa o professor tem a ferramenta necessária para introduzir a literatura, já que insere na discussão práticas de ensino e aprendizagem voltadas à leitura e à escrita e não à transmissão de conhecimentos conceituais. Ao mencionar a leitura e a escrita, a licencianda toma essas práticas como conteúdos de ensino e aprendizagem, reenunciando, desse modo, o discurso teórico daquela disciplina. Porém, logo na sequência, Rute afirma que o objetivo do ensino é a fixação do assunto tratado. Assim, o discurso da licencianda aponta para algo novo que está sendo assimilado por meio das interações no curso, mas que se assenta sob as bases de um discurso bastante solidificado/arregimentado nas práticas escolares: o de professor como transmissor de conteúdos, evocado no tom da palavra fixação.

Iara (AA2), por sua vez, também reenuncia o discurso do professor transmissor de conteúdos, pois embora afirme que a função do professor é intermediar o caminho, a partir da escolha lexical adquirir (o professor é o mediador, que ajuda os alunos a adquirirem conhecimentos), a licencianda reenuncia a identidade do professor transmissor de conhecimentos.

Conforme mostramos aqui a partir dos exemplos, muitas vezes, os licenciandos usam o termo mediador ou mediação, mas no sentido de transmissão de conteúdos. Então, altera-se a terminologia, porém o discurso do professor transmissor de conteúdos/conhecimentos é o que orienta/baliza a voz dos licenciandos.

Nessa mesma atividade avaliativa, também se sobressaíram enunciados que, de certo sentido, hibridizam o discurso sobre o professor transmissor de conhecimentos (mesmo usando o termo mediador) com o discurso sobre o professor mediador oriundo das interações na disciplina Metodologia do Ensino de Língua Portuguesa e Literatura (2011/1), como podemos verificar a seguir:

Afinal, qual é a função do professor de Língua Portuguesa e Literatura? 
AA3-Rose: A função do professor é de mediador entre o conhecimento que o aluno possui e o que precisa ser ensinado. Ele deve promover meios de como fazer seu aluno apropriar-se do conteúdo abordado como também estimulá-lo à posicionar-se de maneira crítica e participativa quando este achar necessário. O professor de Lingua Portuguesa tem, necessariamente, o texto como objeto do ensino da sua disciplina e deve ter o livro didático apenas como material de apoio para suas aulas e escolher o material adequado à sua formação e que atenda as expectativas de seus alunos.

AA4-Fabiane: A função do professor de Língua Portuguesa e Literatura é ser mediador no processo de aprendizagem de seus alunos fazendo uma interligação entre o conhecimento que os alunos já possuem e o que precisa ser ensinado.

Afinal, qual é a função do professor de Lingua Portuguesa e Literatura?

AA5-Bárbara: Ensinar Língua Portuguesa e Literatura é o ato de transferir conhecimentos que adquirimos ao longo de nossos estudos e vivência a alunos ou a quem necessitar de nossa ajuda. Como professor, a transferência de conhecimentos deve ocorrer através da interação com seus alunos em sala de aula, colocando-se como um mediador no processo de ensino e aprendizagem e não como o único conhecedor do assunto que pretende transmitir, estando aberto a aprender junto com seus alunos. Assim, através da mediação, a criança poderá compreender com mais clareza algo que não dominava tão bem, adquirindo novos conhecimentos, ampliando suas estruturas cognitivas.
AA6-Ruana: [...] "No estado de Santa Catarina, a ancoragem metodológica está fortemente pautada em Vygotsky, Luria e Leontiev. Em vista disso, houve um processo de reorientação curricular embasado no pensamento histórico-cultural, e a partir dele a proposta curricular foi construída de forma democrática, com a participação de grupos de trabalho e estudos, envolvendo educadores da rede pública de ensino e professores de universidades como consultores" (PELANDRÉ,2011,p. 28).

Vygostky apud Pelandré, diz que:

[...] o processo de ensino e de aprendizagem constitui-se por meio de interações que vão se dando nos diversos contextos sociais, razão pela qual a sala de aula é lugar privilegiado para a sistematização do conhecimento e o professor passa a ocupar o papel de mediador na construção do saber (PELANDRÉ, 7 2011, p. 28).

$\mathrm{E}$ então, refletindo sobre tudo isso acredito que uma das funções do professor de Língua Portuguesa e Literatura se encaixa perfeitamente nesse conceito apresentado.

Quando as licenciandas (AA3 e AA4) afirmam que a função do professor é ser o mediador entre o conhecimento que o aluno possui e o que precisa ser ensinado e fazer uma interligação entre o conhecimento que os alunos já possuem e o que precisa ser ensinado, renunciam o discurso oriundo das interações com a disciplina em questão. Nesses dizeres há uma alusão ao conceito vigotskiano de zona de desenvolvimento imediato, ${ }^{8}$ apresentado no livro da disciplina.

As licenciandas reenunciam em sua atividade o discurso teórico da disciplina, e o fazem a partir da relação entre a no- 
ção de mediação e a de zona de desenvolvimento imediato, colocando em relevo as teorias pedagógicas discursivizadas nas interações na aula virtual. Isso aponta para um processo de assimilação dessa palavra (palavra teórica/palavra de autoridade da academia), que ainda não é delas, mas que está sendo agenciada pela equipe da disciplina e reenunciada pelas licenciandas. Elas não só devolvem/revozeiam a palavra teórica como também a ressignificam, uma vez que

[...] as palavras do outro, introduzidas na nossa fala, são revestidas inevitavelmente de algo novo, de nossa compreensão, de nossa avaliação, isto é, tornam-se bivocais (BAKHTIN, 2008[1963], p. 223).

Um exemplo disso é que, na resposta de Rose (AA3), há marcas nas escolhas lexicais que apontam para essa relação com o discurso outro, nesse caso, com o discurso teórico. Enquanto Iara (AA2) usa o termo adquirir, Rose (AA3) menciona apropriar-se, como vemos em: Ele [o professor] deve promover meios de como fazer seu aluno apropriar-se do conteúdo abordado como também estimulá-lo à posicionar-se de maneira crítica e participativa quando este achar necessário. Além de afirmar que a função do professor é mediar a apropriação dos conteúdos pelos estudantes, a licencianda expande a discussão ao ponderar sobre os conteúdos de ensino do professor. Ao dizer que $O$ professor de Língua Portuguesa tem, necessariamente, o texto como objeto do ensino da sua disciplina, Rose está reenunciando o discurso teórico oriundo das disciplinas de Linguística Textual e de Linguística Aplicada: Ensino de Língua Materna. O discurso-resposta de Rose evidencia que os discursos teóricos oriundos das interações das disciplinas foram ouvidos, pois a licencianda dialoga com eles, relaciona conteúdos das diferentes disciplinas do curso e, sobretudo, concorda com esses discursos. Vale lembrar que a noção bakhtiniana de diálogo implica tanto concordância quanto discordância; diálogo implica encontro entre diferentes axiologias, e, nesse caso, a licencianda reenuncia a teorização e a assume.

A licencianda também manifesta uma orientação axiológica sobre a relação entre o professor e o livro didático, como verificamos em: [...] e deve ter o livro didático apenas como material de apoio para suas aulas e escolher o material adequado à sua formação e que atenda as expectativas de seus alunos. Nesse trecho do seu enunciado, Rose introduz um já-dito sobre o professor, trata-se da relação do professor com o livro didático na elaboração da aula. Na visão da licencianda, cabe ao professor dirigir a aula e o material didático, uma vez que o professor deve ter o livro didático apenas como material de apoio para suas aulas. Ou seja, o livro didático precisa ser compreendido como suporte do professor e não como o autor da aula. Tal posicionamento remete à necessidade de resgate da função do professor como autor de sua aula. A posição axiológica da licencianda certamente tem ancoragem nos discursos críticos dos estudos da educação e também da área 
de ensino de língua materna, que se corporificam nas discussões das disciplinas do curso voltadas mais especificamente para os temas de ensino e aprendizagem de língua. Nessas disciplinas, não raras vezes, as reflexões problematizam o lugar do livro didático nos processos de ensino e aprendizagem. Assim é que o discurso-resposta da licencianda sobre o resgate da função do professor como autor de sua aula dialoga com outro discurso não-dito, mas que está subentendido - a crítica ao professor como um sujeito que tão somente executa uma partitura pronta e dada de antemão, ao professor como alguém que transmite um saber produzido por outro (GERALDI, 2010a), nesse caso, o autor do livro didático. $\mathrm{O}$ posicionamento da licencianda contrapõe-se à terceira identidade do professor que o vê, conforme Geraldi (2010a), como aquele que aplica um conjunto de técnicas de controle na sala de aula e a quem "compete distribuir o tempo, distribuir as pessoas, e verificar se houve 'fixação' do conteúdo" (GERALDI, 2010a, p. 87).

No discurso de Barbara (AA5), identificamos a menção explícita à identidade do professor como transmissor de conhecimentos e à identidade do professor mediador (Ensinar Língua Portuguesa e Literatura é o ato de transferir conhecimentos que adquirimos [...] colocando-se como um mediador no processo de ensino e aprendizagem). Inicialmente a licencianda afirma explicitamente que ensinar é transferir conhecimento e que cabe ao professor o papel de transmissor. Ao apresentar essa definição, a licencianda parece não compreender ainda que certas escolhas lexicais marcam, na esfera científica, limites entre diferentes modos de teorizar o processo de ensino e aprendizagem. A licencianda parece ainda não ter assimilado este princípio metodológico da ciência: quando se escolhe um termo e não outro, faz-se revelar intravisões sobre campos epistemológicos distintos. Como lembra Bakhtin (2003[1979], as palavras não nos vem como palavras neutras de dicionários, mas de outros enunciados, de onde elas trazem seus sentidos, seus tons. Na esfera científica, usar termos como apropriar-se, construir conhecimentos e, até mesmo, mediar contrapõe-se teoricamente a transferir, adquirir e fixar; dito de outro modo, são discursos distintos. Nesse sentido, assumir que ensinar é transmitir conhecimento mostra adesão a práticas escolares reconhecidas como tradicionais, portanto, é uma visão em grande parte refutada hoje pela ciência e pela esfera escolar. Por outro lado, na sequência, a licencianda diz que essa transferência de conhecimentos se realiza na interação com os alunos e que o professor é o mediador nessa relação. Podemos, portanto, dizer que há um embate entre duas orientações valorativas distintas, já que, no início do enunciado, é reenunciada a identidade do professor transmissor de conhecimentos, construída socialmente e que permeia diversas esferas sociais, apontando para a concepção historicamente constituída de que a escola é um lugar em que se ensina/ transfere o conhecimento acumulado pela sociedade (GERALDI, 2010b). Na sequ- 
ência, esse discurso mais estabilizado choca-se contra o discurso que vem das interações das disciplinas de Linguística Aplicada: Ensino de Língua Materna e de Metodologia do Ensino de Língua Portuguesa e Literatura, cuja perspectiva se pauta na construção de saberes na relação de alteridade entre sujeitos constituídos sócio e historicamente.

Segundo Bakhtin (1998[1975]), na assimilação de vozes, os diferentes discursos disputam entre si para se tornarem discursos interiormente persuasivos. Enfim, há uma arena discursiva a partir do encontro entre os discursos outros já arregimentados socialmente sobre o modo de ver a escola e a atuação do professor e os discursos apresentados no curso de formação inicial. Nessa disputa de vozes, vemos que a licencianda tenta, de fato, apropriar-se do discurso teórico das disciplinas. Observamos um esforço em explicar e agenciar os conceitos teóricos com os quais ela se deparou nas interações das disciplinas. E, embora afirme que é função do professor transferir conhecimento, ela salienta a questão da interação e da mediação; menciona $o$ processo de ensino e aprendizagem e faz referência ao aluno, o outro a quem se destina a ação pedagógica ([...] deve ocorrer através da interação com seus alunos em sala de aula, colocando-se como um mediador no processo de ensino e aprendizagem e não como o único conhecedor do assunto que pretende transmitir, estando aberto a aprender junto com seus alunos. Assim, através da mediação, a criança poderá compreender com mais clareza algo que não dominava tão bem.).

O enunciado de Ruana (AA6), por sua vez, revozeia o discurso teórico com menos apropriação que os exemplos anteriores, uma vez que constrói o seu discurso-resposta quase que integralmente a partir de uma citação literal (discurso relatado direto) do livro da disciplina de Metodologia do Ensino de Língua Portuguesa e Literatura. Ruana (AA6) apresenta suas respostas ao questionário agrupadas em um único texto, ao contrário da maioria dos licenciandos, que respondem separadamente as questões propostas na atividade avaliativa, ou seja, em forma de pergunta e resposta como em um questionário. No final de seu texto, quando discorre sobre a função do professor de Língua Portuguesa, a licencianda responde por meio de uma reenunciação integral, em forma de discurso citado, de um fragmento do livro dessa disciplina. Ela insere esse discurso em massa, de forma compacta, sem contrapor ou comentar, isso porque é um discurso de autoridade (BAKHTIN, 1998[1975]). Ela enquadra esse discurso no interior de sua resposta e concede a ele (discurso citado) a tarefa de responder a questão proposta na atividade. A licencianda conclui seu texto remetendo novamente à voz de autoridade, que é materializada pela reenunciação da teoria: $E$ então, refletindo sobre tudo isso acredito que uma das funções do professor de Língua Portuguesa e Literatura se encaixa perfeitamente nesse conceito apresentado. Nesse parágrafo conclusivo do seu enunciado, novamente a licencian- 
da faz a remissão ao livro da disciplina, sem que haja uma retomada conceitual ou acréscimos ao já-dito pelo livro. $\mathrm{O}$ discurso citado responde a questão; não há comentário, discussão, discordância ou concordância da licencianda; há somente a inserção cabal e definitiva da voz de autoridade, na qual ela deposita a responsabilidade do seu dizer.

Por fim, destacaram-se os enunciados em que o discurso sobre o professor mediador foi relacionado de maneira mais explícita aos conteúdos de ensino próprios do trabalho do professor de Língua Portuguesa, como se observa a seguir:

Afinal, qual é a função do professor de Lingua Portuguesa e Literatura?

AA7-Fernanda: Ampliar as diferentes modalidades da língua, oralidade, escuta, leitura, análise linguística. Apresentar conteúdos novos, ter clareza dos conhecimentos e da linguagem em uso, o professor é o mediador.

AA8-Luciana: A função do professor é ser mediador do aluno para esses obras literárias. Fazer com que o aluno sintase atraído pela leitura, envolvido pelos enredos, sedento de mais e mais aventuras como o sultão de Xerazade.

De maneira geral, como você vê o professor de Lingua Portuguesa hoje? O que é ser professor de Lingua Portuguesa hoje?

Q6: O professor de Língua Portuguesa é um mediador para o ensino imanente da língua, e o que espero dele.

Q7: A maioria das disciplinas cursadas fazem refletir o papel do professor da língua portuguesa como um mediador da aprendizagem, que de, junto aos alunos elabora o conhecimento da estrutura da língua e de seus sentidos.

Q8: Hoje em dia o professor de Língua Portuguesa enfrenta muitos desafios e é visto como o "salvador da Pátria", aquele que precisa alfabetizar, ensinar a ler e escrever... Eu vejo como o mediador, a ponte entre o aluno e as práticas de leitura e escrita....

Ao contrário dos colegas que tematizam o professor mediador de forma ampla e vaga, sem relacionar essa discussão às especificidades do professor de Língua Portuguesa, estes licenciandos focalizam de modo mais pontual a mediação de conteúdos de ensino e aprendizagem próprios da disciplina. No entanto, vale destacar que, ao mencionar os conteúdos mediados pelo professor de Língua Portuguesa, emergem diferentes concepções do que seja conteúdo de ensino na disciplina (obras literárias, ensino da língua vista de modo imanente, estrutura da língua, oralidade, leitura, escrita, análise linguística), bem como a noção de mediação, novamente, aproxima-se da noção de transmissão de conteúdo ou do mediador como aquele que está entre o conhecimento e o aluno.

O discurso-resposta de Fernanda (AA7) e Luciana (AA8), por exemplo, difere dos demais licenciandos, que falam de forma mais genérica sobre a função do professor de Língua Portuguesa (conhecimentos, conteúdos, matéria, etc.). No mais, como já dito, os enunciados dessas licenciandas remetem, de forma explí- 
cita, às especificidades da disciplina de Língua Portuguesa, quando mencionam conteúdos de ensino e aprendizagem dessa disciplina. Fernanda e Luciana também tematizam a identidade do professor como mediador em uma perspectiva de interposição entre conteúdos e alunos, mas transcendem a essa visão na medida em que tematizam como conteúdos de ensino do professor: oralidade, escuta, leitura, análise linguística e conteúdos literários, que, de modo geral, não são conteúdos conceituais que possam ser transmitidos ao aluno.

Ao dizer que o professor é mediador da aprendizagem e não um mediador de conteúdo (um mediador da aprendizagem, que de, junto aos alunos elabora o conhecimento da estrutura da língua e de seus sentidos), o foco do licenciando (Q7) recai sobre a prática (ainda que enfoque como conteúdo de ensino apenas a língua na sua estrutura), levando em conta o aluno, que é um outro na tríade do ensino - professor, aluno e conhecimento. Quando afirma que professor e aluno juntos elaboram o conhecimento sobre a estrutura da língua e os sentidos, o licenciando destaca a interação entre os interlocutores na dinâmica de sala de aula. O uso da palavra mediador, nessa situação, em certo sentido, põe em relevo a interação, imprescindível à mediação.

Já Q8, ao discursivizar o papel de professor como um mediador, primeiramente reenuncia os já-ditos sobre o professor, como se observa no excerto: Hoje em dia o professor de Língua Portuguesa enfrenta muitos desafios e é visto como o "salvador da Pátria", aquele que precisa alfabetizar, ensinar a ler e escrever. Após essa inserção de discursos outros, apresenta sua perspectiva ao afirmar que: Eu vejo como o mediador, a ponte entre o aluno e as práticas de leitura e escrita, refutando, desse modo, os já-ditos que ele mesmo apresenta no seu discurso-resposta. Nessa fala, vemos um movimento de reenunciação e enquadramento valorativo de alguns já-ditos e, na sequência, o estabelecimento da posição axiológica do licenciando, marcando distanciamento de tais discursos. Tal movimento discursivo evidencia o modo como o licenciando está apropriando-se de certos dispositivos comumentemente mobilizados na esfera acadêmica, como, por exemplo, a prática de enunciar discursos alheios para se aproximar, avaliar, refutar etc. Muito embora a metáfora da ponte esteja também presente nesse enunciado, quando o licenciando afirma que compreende o professor como um mediador entre o aluno e as práticas de leitura e escrita, emergem sentidos constituídos/mobilizados no próprio curso, mais especificamente, oriundos das disciplinas cursadas naquele mesmo período (Linguística Aplicada: Ensino de Língua Materna e Metodologia do Ensino de Língua Portuguesa e Literatura, ambas ministradas em 2011/1). Isso aponta para uma assimilação das teorias contempladas em algumas das disciplinas, tendo em vista que essa reenunciação revela os modos de 
apreensão desse discurso teórico.Como podemos observar na análise dos dados, os licenciandos, ao tratar da identidade do professor, compreendem-na pela ótica do professor mediador, ora de modo mais amplo, ora focalizando a mediação a partir da disciplina de Língua Portuguesa (finalidade, conteúdos etc.). E mais, observamos que o discurso do professor mediador encontra-se na confluência de vários discursos: o discurso da mediação tal como entendida por Vigotski e Bakhtin, o discurso da mediação como estar entre o conteúdo e o professor e $o$ discurso da mediação entendido como sendo transmissão de conteúdos, com certa predominância da compreensão do professor mediador como alguém que se interpõe entre o aluno e o objeto de conhecimento, ou seja, o professor que transmite um saber.

\section{Considerações finais}

A análise aqui apresentada mostrou que a discursividade sobre a atuação do professor de Língua Portuguesa foi constituída nos processos históricos por que passou a constituição da disciplina no sistema escolar, evidenciando alguns discursos já-ditos sobre a identidade do professor. Observamos que o discurso dos licenciandos tematizam e valoram a relação entre o professor e o conhecimento, seja o teórico, seja o de ensino e aprendizagem em sala de aula, considerando-o como constitutivo para a formação desse profissional. Essa relação se evidenciou principalmente em enunciados que remetiam à noção de professor como mediador do conhecimento.

A análise dos dados nos permitiu observar que os discursos científico e da formação inicial, enunciados nas interações do curso, nos processos de apropriação pelos lincenciados são por estes ressignificados (como era de se esperar com qualquer apropriação discursiva). Nesse contexto, como demonstrado pela análise, o professor mediador foi discursivizado, na maioria das vezes, como alguém que está entre o conhecimento e 0 aluno. Isso, não raras vezes, remeteu ao sentido de transposição de conteúdos, ou seja, houve uma mudança terminológica, mas não conceitual acerca da identidade do professor e do seu papel em sala de aula, o que, de certo modo, nos mostra a prevalência do discurso da tradição sobre o discurso da mudança no ensino e aprendizagem de Língua Portuguesa.

\section{The discourse about the} teacher as a Mediator: a reflection on discursive productions of undergraduates in Distance Education

\section{Abstract}

This paper presents an analysis of discursive productions of undergraduate students attending a course of Letters-Portuguese-Distance Learning, at a public university in southern Brazil. We aim to investigate the construction of identity of the Portuguese language teacher. The theoreti- 
cal and methodological foundation is based on the studies of the Bakhtin Circle. The data under analysis comprise 106 discussion forums; 59 enunciations of evaluative activities posted in the virtual environment for teaching and learning in the period of 2007 to 2011; and data generated by means of a questionnaire answered by 61 undergraduates. The analysis of the discursive productions of the students points to the re-enunciation of various discourses about the teacher, including the teacher as a mediator. The mediator teacher is signified by the licensees as a mediator of knowledge, as someone who stands between the knowledge and the student, which is associated to the idea of knowledge transposition.

Keywords: Discursive production in Distance Education. Initial teacher education. Mediator teacher. Bakhtin Circle.

\section{Notas}

1 Adotamos a noção de geração/constituição de dados nos embasando na pesquisa de Rodrigues (2011).

2 Nesse texto, Geraldi retoma o que já dizia em Portos de Passagem. Embora haja reformulações no texto de 2010 , esse olhar para a constituição do professor já estava presente na obra de 1991.

3 Trata-se do professor que já não mais produz o conhecimento.

4 Incluímos a noção de conhecimentos culturais como aqueles cristalizados na sociedade e nem sempre considerados como conhecimentos científicos, a exemplo de muitas posições de que o conhecimento sistematizado nas gramáticas tradicionais não pode ser considerado como conhecimento científico.

5 Nesse texto, a pesquisadora discute as diferenças entre professor mediador e professor como agente de letramento.

6 Os dados inseridos no corpo da análise correspondem exatamente ao que foi textualizado pelos sujeitos da pesquisa, ou seja, não hou- ve nenhuma espécie de revisão de texto. $\mathrm{O}$ destaque em negrito, inserido em partes dos enunciados, ressalta o tópico em análise. Para indicar a natureza do dado inserido na análise, utilizamos as seguintes siglas: $A A-$ Atividades Avaliativas; F-Fórum;e Q-Questionário. Vale destacar que os nomes dos sujeitos mencionados na transcrição dos dados são fictícios.

7 A referência completa do livro é: PELANDRÉ, Nilcéa; BORTOLOTTO, Nelita; MONGUILHOTT, Isabel de Oliveira e Silva; DEBUS, Eliane Santana Dias. Metodologia do Ensino de Lingua Portuguesa e Literatura. Florianópolis: DLLV-CCE-UFSC, 2011.

8 Segundo Vigotski (1991[1984], p. 58), a zona de desenvolvimento imediato é compreendida como "a distância entre o nível de desenvolvimento real, que se costuma determinar através da solução independente de problemas, e o nível de desenvolvimento potencial, determinado através da solução de problemas sob a orientação de um adulto ou em colaboração com companheiros mais capazes".

\section{Referências}

AMORIM, Marília. O pesquisador e seu outro: Bakhtin nas ciências humanas. São Paulo: Musa Editora, 2004.

BAKHTIN, Mikhail M.; [VOLOCHÍNOV, V. N.]. Marxismo e filosofia da linguagem: problemas fundamentais do método sociológico na ciência da linguagem. 11. ed. Tradução do francês por Michel Lahud e Yara F.Vieira. São Paulo: Hucitec, 2004[1929].

Problemas da poética de Dostoiévski. Tradução do russo, notas e prefácio de Paulo Bezerra. 4. ed. Revista e ampliada. Rio de Janeiro: Forense Universitária, 2008[1963].

Questões de literatura e de estética - a teoria do romance. Tradução do russo por Aurora Fornoni Bernardini et al. São Paulo: UNESP; Hucitec, 1998[1975].

. Estética da criação verbal. Tradução do russo por Paulo Bezerra. 4. ed. São Paulo: Martins Fontes, 2003[1979].

BRAIT, Beth. Análise e Teoria do Discurso. 
In: BRAIT, B. (Org.). Bakhtin: Outros Conceitos-chave. São Paulo: Contexto, 2006. p. 9-31.

A natureza dialógica da linguagem: formas e graus de representação dessa dimensão constitutiva. In: FARACO, C. A.; TEZZA, C.; CASTRO, G. Diálogos com Bakhtin, 4. ed. Curitiba: Editora da UFPR, 2007. p. 61-80.

BRASIL. Secretaria de Educação Fundamental. Parâmetros Curriculares Nacionais: terceiro e quarto ciclos do ensino fundamental: introdução aos parâmetros curriculares nacionais. Brasília: MEC/SEF, 1998.

BRITTO, Luiz Percival Leme. A sombra do caos: ensino de língua x tradição gramatical. Campinas (SP): Mercado de Letras, 1997.

CAVALCANTI, Marilda C. Um olhar metateórico e metametodológico em pesquisa em Lingüística Aplicada: implicações éticas e políticas. In: MOITA LOPES, Luiz Paulo. (Org.). Por uma linguística aplicada indisciplinar. São Paulo: Parábola, 2006. p. 233-252.

FARACO, Carlos Alberto. Linguagem \& diálogo: as idéias lingüísticas do Círculo de Bakhtin. São Paulo: Parábola, 2009[2003].

FREIRE, Paulo. Pedagogia do oprimido. 40. ed. Rio de Janeiro: Paz e Terra, 2005[1970].

. Pedagogia da autonomia: saberes necessários à prática educativa. 34. ed. Rio de Janeiro: Paz e Terra. 2006[1996].

GERALDI, João Wanderley. A aula como acontecimento. São Carlos: Pedro \& João Editores, 2010a.

. Ancoragens: estudos bakhtinianos. São Carlos: Pedro \& João Editores, 2010b.

KLEIMAN, Angela B. Processos identitários na formação profissional: o professor como agente de letramento. In: CORREAA, Manoel L. G; BOCH, Françoise. (Orgs.). Ensino de Língua: representação e letramento. Campinas: Mercado de Letras, 2006. p. 75-91.
PELANDRÉ, Nilcéa; BORTOLOTTO, Nelita; MONGUILHOTT, Isabel de Oliveira e Silva; DEBUS, Eliane Santana Dias. Metodologia do Ensino de Língua Portuguesa e Literatura. Florianópolis: DLLV-CCE-UFSC, 2011.

ROJO, Roxane Helena Rodrigues. Modelização Diadática e planejamento: duas práticas esquecidas do professor?. In: KLEIMAN, Ângela B. (Org.). A formação do professor: perspectivas da lingüística aplicada. Campinas, SP: Mercado das Letras, 2001. p. 313-335.

RODRIGUES, Nara Caetano. A construção dialógica do discurso do professor de língua portuguesa. São Carlos: Pedro \& João Editores, 2011. 232p.

RODRIGUES, Rosângela Hammes. Pesquisa com os gêneros do discurso na sala de aula: resultados iniciais. Acta Scientiarum Language and Culture. v. 3. n. 2, p. 169-175, 2008. Disponível em: < http://periodicos.uem. br/ojs/index.php/ActaSciLangCult/article/ view/6004/6004> Acesso em: 20 out. 2011.

SOARES, Magda. Português na escola - História de uma disciplina curricular. In: BAGNO, Marcos (Org.). Lingüística da norma. São Paulo: Edições Loyola, 2002. p. 155-177.

SOBRAL, Adail. Ético e estético: na vida, na arte e na pesquisa em Ciências Humanas. In: BRAIT, B. Bakhtin: conceitos-chave. 4. ed. São Paulo: Contexto. 2007. p. 11-36.

VIGOTSKI, Lev Semionovich. A formação social da mente. São Paulo: Martins Fontes, 1991[1984]. 